\title{
Seroprevalence of Tissue and Luminal Helminths among Patients in Hanoi Medical University Hospital, Vietnam, 2018
}

\author{
Nguyen Van De ${ }^{1, *}[$, Pham Ngoc Minh', Nguyen Ngoc Bich', Jong-Yil Chai² \\ 'Department of Parasitology, Hanoi Medical University, Hanoi, Vietnam; 'Institute of Parasitic Diseases, Korea Association of Health Promotion, \\ Seoul 07649, and Department of Tropical Medicine and Parasitology, Seoul National University College of Medicine, Seoul 03080, Korea
}

\begin{abstract}
A serological survey was performed using ELISA to estimate the prevalence of tissue and luminal helminthic infections among hospital patients in Hanoi region, Vietnam. An overall seroprevalence of tissue and luminal helminthiases was $64.0 \%$ (95\% Cl 61.2-66.8) among 1,120 patients who visited Hanoi Medical University Hospital, Vietnam in 2018. The highest seroprevalence was observed against Toxocara spp. (59.0\%), followed by Strongyloides stercoralis (46.3\%), Gnathostoma spp. (25.5\%), cysticercus (12.8\%), Angiostrongylus cantonensis (10.5\%), Fasciola spp. (11.1\%), and Clonorchis sinensis (8.7\%). Mono-infection by one species $(11.1 \%)$ was lower than multiple infections $(53.0 \%)(P<0.05)$. The seroprevalence in males (59.3\%) was lower than in females (66.2\%) but not statistically significant $(P>0.05)$. Children $(<15$ years) revealed lower seroprevalence (34.0\%) than adults (68.4\%), and the age group 51-70 years revealed the highest seroprevalence $(76.0 \%)$. Among the seropositive patients, eosinophilia $(\geq 8.0 \%)$ was noted in $80.2 \%$. The present results suggested active transmission of various tissue and luminal helminths among people in Hanoi, Vietnam.
\end{abstract}

Key words: Toxocara spp., Strongyloides stercoralis, Gnathostoma spp., Angiostrongylus cantonensis, Fasciola spp., Clonorchis sinensis, cysticercus, seroprevalence, Vietnam

\section{INTRODUCTION}

Helminthiases are widely spread around the world, especially in tropical areas, where local people have poor hygiene and lower income economies, such as Africa and Asia, including Vietnam. For example, human fascioliasis has been reported in more than 70 countries in Europe, the Middle East, Latin America, the Caribbeans, Africa, Asia, and Oceania [1]. Clonorchiasis is distributed in many countries such as South Korea, China, Taiwan, Vietnam, Japan, and Russia with 35 million infected cases in the world, including 15 million in China [2]. Toxocariasis is widespread, including the Americas, Japan, Canada, Germany, England, Italy, France, and Russia; in some areas the infection rate is up to $35-42 \%$ [3]. Based on serological examinations, the prevalence of toxocariasis has been reported to be 30-93\% in developing countries [3]. Angiostrongyliasis due to Angiostrongylus cantonensis is distributed in more

\footnotetext{
- Received 13 June 2020, revised 10 July 2020, accepted 10 July 2020.

*Corresponding author (ngvdeyhn@gmail.com)

(C) 2020, Korean Society for Parasitology and Tropical Medicine

This is an Open Access article distributed under the terms of the Creative Commons

Attribution Non-Commercial License (https://creativecommons.org/licenses/by-nc/4.0) which permits unrestricted non-commercial use, distribution, and reproduction in any

medium, provided the original work is properly cited.
}

than 30 countries in Asia, Africa, the Caribbeans, Australia, and USA (Hawaii and Louisiana) with over 2,800 cases [4]. Strongyloidiasis caused by Strongyloides stercoralis is also widespread in the world with 30-100 million cases and are the cause of diseases of the intestine, lungs, skin, and others [5]. Gnathostomiasis has been detected in many countries, including Japan, Thailand, Cambodia, Laos, Myanmar, Indonesia, the Philippines, Malaysia, Vietnam, China, India, and Sri Lan$\mathrm{ka}[6,7]$. Cysticercosis due to infection with the metacestode of Taenia solium is distributed in wide areas of Asia, Africa, the Americas, and Oceania. In some areas, the prevalence of cysticercosis was $10 \%$ where neurocysticercosis was the cause of severe cerebral diseases [8].

In Vietnam, helminthic diseases are distributed all over the country, including fascioliasis in 63 of 63 provinces, clonorchiasis/opisthorchiasis in 32 of 63 provinces, and cysticercosis in 50 of 63 provinces; toxocariasis, strongyloidiasis, angiostrongyliasis, and gnathostomiasis are detected in every province of the country [9-12]. However, there have been no recent data to estimate the present status of these helminthic infections among hospital patients around Hanoi region. Therefore, the present study was performed to estimate the prevalence of tissue and luminal helminthiases, including toxocari- 
asis, strongyloidiasis, gnathostomiasis, cysticercosis, fascioliasis, angiostrongyliasis, and clonorchiasis, using ELISA among the patients who visited Hanoi Medical University Hospital during 2018 (from 27 of 28 northern provinces), Hanoi, Vietnam.

\section{MATERIALS AND METHODS}

\section{Sample collection}

A total of 1,120 patients from 5 to $>70$ years-old who visited Hanoi Medical University Hospital in 2018 for serological examinations for helminthiasis were subjected in this study. Hanoi Medical University Hospital receives patients from throughout the entire country; however, in this study only patients from northern Vietnam were considered for convenience. ELISA test for detection of antibodies against parasitic agents was applied as a routine diagnosis by the Parasitology Laboratory of the hospital. All patients agreed to this study, including adults and children from 5-16 year-olds who gave consent through their parents.

\section{Data analyses}

The reason why the patients came to the hospital was collected for this study, 1 main symptom per patient only. Blood samples of all patients were analyzed for helminthic infections with an IgG ELISA test kit (DRG Instruments GmbH, Springfield, Illinois, USA), including toxocariasis, strongyloidiasis, gnathostomiasis, cysticercosis, fascioliasis, angiostrongyliasis, and clonorchiasis. The sensitivity and specificity of ELISA for these helminthic diseases were both satisfactory ( $>95 \%$; data not shown). The seroprevalence was analyzed by locality of origin (from each province), mono-/multi-infection, gender (male/female), age groups (5-15; 16-30; 31-50; 51-70; and $>70$ years-old), and eosinophilia ( $\geq 8 \%$, according to the normal physiology of Vietnamese inhabitants).

\section{RESULTS}

\section{Chief complaints of patients}

The main reasons (i.e., chief complaint) why 1,120 patients
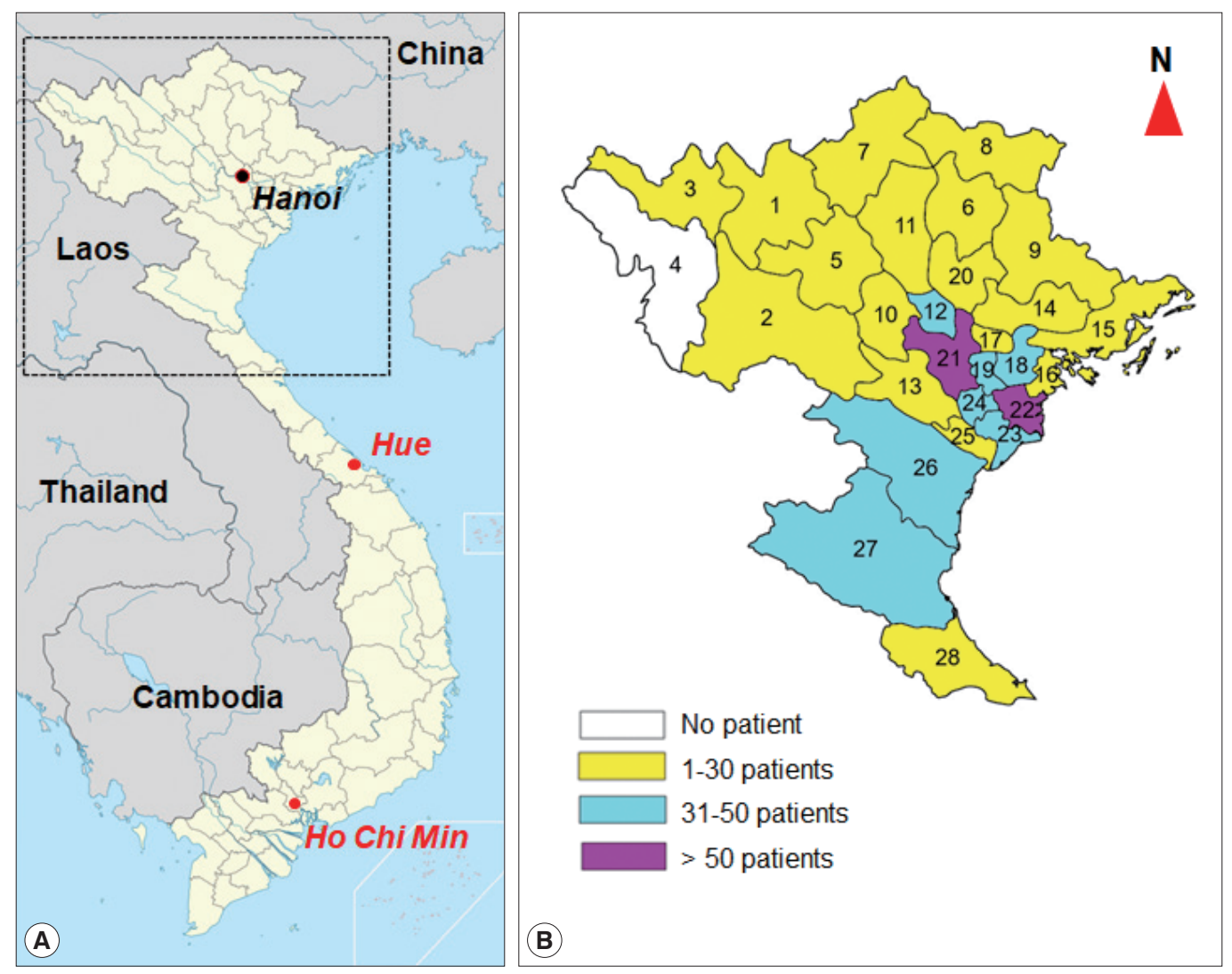

Fig. 1. Map of Vietnam showing administrative divisions of provinces. (A) Location of Vietnam in Southeast Asia (source: google). (B) Map of 28 provinces in northern Vietnam (magnification of the boxed area in Fig. 1A) showing the number of patients who visited Hanoi Medical University Hospital by different colors (for province names see corresponding numbers in Table 1). 
came to the hospital was headache $26.6 \%$, stomachache $23.7 \%$, digestive disorders $16.0 \%$, allergy $13.6 \%$, fever $10.3 \%$, cough $7.1 \%$, and loss of body weight $2.9 \%$.

\section{Geographical distribution in northern Vietnam}

Twenty seven of 28 northern provinces (Fig. 1) had patients who visited Hanoi Medical University Hospital for examination of tissue or luminal helminth infections. The largest number came from Hanoi (112 patients), followed by Thai Binh (101), while the lowest numbers from Dien Bien and Bac Kan Province (Table 1).

\section{Prevalence of helminthiasis}

Of the 1,120 serum samples tested by ELISA, the overall helminthic infection rate was $64.0 \%$, including Toxocara spp. infection 59.0\%, Strongyloides stercoralis infection 46.3\%, Gna-

Table 1. Distribution of patients according to provinces (see Fig. 1B)

\begin{tabular}{|c|c|c|c|c|}
\hline Serial no. & Province & $\begin{array}{c}\text { No. of } \\
\text { patients } \\
\text { examined }\end{array}$ & $\begin{array}{l}\text { No. cases } \\
\text { seropositive }\end{array}$ & $\%$ \\
\hline 1 & Lao Cai & 24 & 17 & 70.8 \\
\hline 2 & Son La & 34 & 22 & 64.7 \\
\hline 3 & Lai Chau & 16 & 12 & 75.0 \\
\hline 4 & Dien Bien & 0 & 0 & 0.0 \\
\hline 5 & Yen Bai & 36 & 24 & 66.7 \\
\hline 6 & Bac Kan & 12 & 8 & 66.7 \\
\hline 7 & Ha Giang & 23 & 15 & 65.2 \\
\hline 8 & Cao Bang & 20 & 13 & 65.0 \\
\hline 9 & Lang Son & 21 & 14 & 66.7 \\
\hline 10 & Phu Tho & 48 & 30 & 62.5 \\
\hline 11 & Tuyen Quang & 24 & 16 & 66.7 \\
\hline 12 & Vinh Phuc & 51 & 31 & 60.8 \\
\hline 13 & Hoa Binh & 36 & 24 & 66.7 \\
\hline 14 & Bac Giang & 44 & 29 & 65.9 \\
\hline 15 & Quang Ninh & 34 & 23 & 67.7 \\
\hline 16 & Hai Phong & 24 & 15 & 62.5 \\
\hline 17 & Bac Ninh & 35 & 22 & 62.9 \\
\hline 18 & Hai Duong & 57 & 35 & 61.4 \\
\hline 19 & Hung Yen & 70 & 44 & 62.9 \\
\hline 20 & Thai Nguyen & 31 & 20 & 64.5 \\
\hline 21 & Hanoi & 112 & 67 & 59.8 \\
\hline 22 & Thai Binh & 101 & 63 & 62.4 \\
\hline 23 & Nam Dinh & 50 & 32 & 64.0 \\
\hline 24 & $\mathrm{Ha} \mathrm{Nam}$ & 52 & 33 & 63.5 \\
\hline 25 & Ninh Binh & 24 & 15 & 62.5 \\
\hline 26 & Thanh Hoa & 47 & 31 & 66.0 \\
\hline 27 & Nghe An & 54 & 35 & 64.8 \\
\hline \multirow[t]{2}{*}{28} & Ha Tinh & 40 & 27 & 67.5 \\
\hline & Total & 1,120 & 717 & 64.0 \\
\hline
\end{tabular}

thostoma spp. infection $25.5 \%$, cysticercosis $12.8 \%$, Fasciola spp. infection $11.2 \%$, Angiostrongylus cantonensis infection 10.5\%, and Clonorchis sinensis infection 8.7\% (Table 2).

\section{Mono-infection and multiple infections}

The proportion of patients with mono-infection (11.1\%) was lower than that with multiple infections $(53.0 \%)(P<0.05)$. Toxocara mono-infection was 3.1\% (multiple infections with Toxocara spp. and other helminths, 55.9\%), and Strongyloides mono-infection was $2.3 \%$ (multiple infections, $44.0 \%$ ). Mono-infection of Fasciola was 2.1\% (multiple infections, 23.4\%), and those of Angiostrongylus and Gnathostoma were 1.3\% (multiple infections, $11.4 \%$ ) and $0.98 \%$ (multiple infections, $10.2 \%)$, respectively. Cysticercus mono-infection was $0.71 \%$ (multiple infections, 9.8\%), and C. sinensis mono-infection was $0.45 \%$ (multiple infections, $8.2 \%$ ).

\section{Helminthic infections according to gender}

The seroprevalence of helminths in males (59.3\%) was lower than that in females (66.2\%) but without statistical significance (Table 3). Toxocara infection in males (55.9\%) was lower than that in females (60.4\%), and Strongyloides infection in males (43.8\%) was slightly lower than that in females (47.5\%). Gnathostoma infection was similar in males $(25.7 \%)$ and females (25.5\%), and cysticercosis was lower in males (14.4\%) than in females (12.0\%). Fasciola infection was slightly lower in males (10.7\%) than in females (11.4\%), and Angiostrongylus infection was lower in males (9.4\%) than in females (11.2\%) but without statistical significance in both infections. The gender difference in the seroprevalence was statistically significant only in Clonorchis infection; its prevalence was significantly higher in males (12.1\%) than in females (6.8\%) (Table 3).

Table 2. Seroprevalence of helminthic infections among patients who visited Hanoi Medical University Hospital (2018)

\begin{tabular}{lcc}
\hline & No. posit. (\%) & $95 \% \mathrm{Cl}^{\mathrm{a}}(\%)$ \\
\hline No. examined & 1,120 & \\
No. any helminth positive & $717(64.0)$ & $61.2-66.8$ \\
Toxocariasis & $661(59.0)$ & $56.1-61.9$ \\
Strongyloidiasis & $519(46.3)$ & $43.4-49.3$ \\
Gnathostomiasis & $286(25.5)$ & $23.0-28.1$ \\
Cysticercosis & $143(12.8)$ & $10.8-14.7$ \\
Fascioliasis & $125(11.2)$ & $9.3-13.0$ \\
Angiostrongyliasis & $118(10.5)$ & $8.7-12.3$ \\
Clonorchiasis & $97(8.7)$ & $7.0-10.3$ \\
\hline
\end{tabular}

${ }^{a}$ Confidence interval. 
Table 3. Seroprevalence of helminthic infections according to gender

\begin{tabular}{|c|c|c|c|c|}
\hline & \multicolumn{4}{|c|}{ No. of seropositive cases } \\
\hline & Males (\%) & Females (\%) & Relative rate ${ }^{a}$ & $P$-value ${ }^{b}$ \\
\hline No. examined & 354 & 766 & - & - \\
\hline Overall positive cases & $210(59.3)$ & 507 (66.2) & 0.896 & $>0.05$ \\
\hline Toxocariasis & $198(55.9)$ & $463(60.4)$ & 0.925 & $>0.05$ \\
\hline Strongyloidiasis & $155(43.8)$ & $364(47.5)$ & 0.922 & $>0.05$ \\
\hline Cysticercosis & $51(14.4)$ & $92(12.0)$ & 1.200 & $>0.05$ \\
\hline Fascioliasis & $38(10.7)$ & $87(11.4)$ & 0.945 & $>0.05$ \\
\hline Angiostrongyliasis & $32(9.0)$ & $86(11.2)$ & 0.805 & $>0.05$ \\
\hline Clonorchiasis & $45(12.7)$ & $52(6.8)$ & 1.872 & $<0.05$ \\
\hline
\end{tabular}

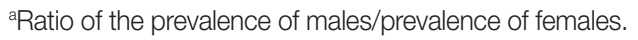

bStatistical significance between the prevalence of males and females.

Table 4. Seroprevalence of helminthic infections according to age group

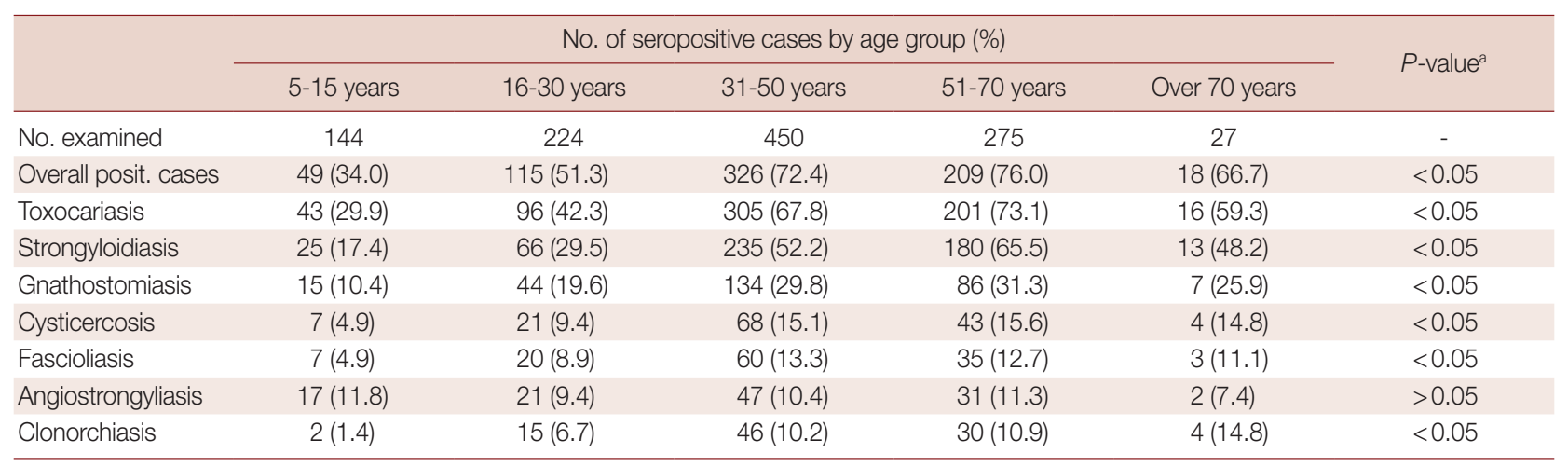

${ }^{a} P$-value between the age group 5-15 years vs sum of all other groups (16-30, 31-50, 51-70, and over 70 years).

\section{Helminthic infections according to age group}

The prevalence of helminthic infections was the highest in 51-70 years $(76.0 \%)$ followed by $31-50$ years $(72.4 \%)$ and the lowest in 5-15 years group (34.0\%) (Table 4). With the exception of angiostrongyliasis and clonorchiasis, the seroprevalence was the highest in 31-70 years of age (72.4-76.0\%) compared with other age groups (Table 4). In angiostrongyliasis, 5-15 years group showed the highest seroprevalence (11.8\%), and in clonorchiasis, the highest prevalence was observed in $>70$ years group (14.8\%) (Table 4 ).

Overall, the seroprevalence of helminthiasis was lower in children (34.0\%) than in adults (68.4\%) with positive statistical significance. Toxocara infection in children (29.9\%) was significantly lower than that of adults (63.3\%), and Strongyloides infection in children (17.4\%) was markedly lower than that of adults (50.6\%). Gnathostoma infection in children (10.4\%) was significantly lower than that of adults (27.8\%), and cysticercosis in children (4.9\%) was significantly lower than that of adults (13.9\%). Fasciola infection in children (4.9\%) was also significantly lower than in adults (12.1\%), and clonorchiasis in children (1.4\%) was markedly lower than in adults (9.7\%). No age tendency was observed in the seroprevalence of Angiostrongylus infection in children (11.8\%) vs adults (10.4\%).

\section{Eosinophilia by helminthic infections}

Most (80.2\%) of the helminth-infected patients had eosinophilia ( $\geq 8.0 \%)$, and a few $(18.8 \%)$ seropositive patients revealed normal eosinophil $(<8.0 \%)$ levels.

\section{Helminthiasis according to the time of months in the year}

The patients who visited our hospital for diagnosis and treatment of helminthiases came during every month of the year but the number of patients was different by month. The number of patients increased from January to the highest in June, and decreased thereafter to December (data not shown). 


\section{Anthelmintic treatment of seropositive patients}

The seropositive patients were treated with anthelmintic drugs. In toxocariasis and gnathostomiasis patients, albendazole $15 \mathrm{mg} / \mathrm{kg}$ body weight/day $\times 21$ days was given; strongyloidiasis patients were given ivermectin $0.2 \mathrm{mg} / \mathrm{kg} /$ day for 2 days; angiostrongyliasis patients were prescribed albendazole $15 \mathrm{mg} / \mathrm{kg} \times 15$ days; cysticercosis patients was treated with praziquantel $15 \mathrm{mg} / \mathrm{kg}$ in a single dose in the first day and then albendazole $7.5 \mathrm{mg} / \mathrm{kg} \times 2$ times a day $\times 20$ days; fascioliasis patients were given triclabendazole $10 \mathrm{mg} / \mathrm{kg} \times 2$ times a day for 1 day; clonorchiasis patients were treated with praziquantel $25 \mathrm{mg} / \mathrm{kg} \times 3$ times a day for 2 days.

\section{DISCUSSION}

The most common reasons (clinical complaints) for the patients who came to the hospital included headache (26.6\%) and stomachache $(23.7 \%)$. Of the 1,120 patients who were from 27 of 28 northern provinces in Vietnam and came to Hanoi University Hospital for examination, $64.0 \%$ (717 patients) showed seropositive results for tissue or luminal helminthiasis. The number of patients from Hanoi City was the highest (112 patients) but the helminthic infection rate was the lowest (59.8\%); the highest infection rate was observed from Lai Chau Province (75.0\%).

Toxocara spp. infection rate was 59.0\%, which was the highest in this study compared to previous reports [11-15]. In the laboratory of hospitals and medical centers, Toxocara infection was $45.2 \%$ [12] and $65.1 \%$ [13] before this report. In the community, Toxocara infection was $24.4 \%$ in southern provinces [14] and $17 \%$ in middle provinces [15]. The seroprevalencse of toxocariasis was reported from other countries; in Nigeria 30\%, Brazil 36\%, Swaziland 44.6\%, Malaysia 58\%, Indonesia 63.2\%, Nepal 81\%, Marshall Islands 86.8\%, and La Reunion $93 \%[3,16]$. The prevalence of Toxocara in rural areas was higher than that in urban areas (35-42\% and $2-5 \%$, respectively) [3]. The remarkably high seroprevalence of toxocariasis in northern Vietnam is probably due to high soil contamination with canine (Toxocara canis) or feline (Toxocara cati) feces containing the infective eggs.

The seroprevalence of $S$. stercoralis infection in this study was 46.3\%. In other studies from Hanoi Hospital, the prevalence was was 20.0\% [17], and in Ho Chi Minh Hospital 29.0\% among the stomachache patients group [11]. In the laboratories, the prevalence was $22.5 \%$ [13] and $7.4 \%$ [12], and in the community $7.6 \%$ [18] and $17.3 \%$ [14]. S. stercoralis prevalence in other countries was $17.5 \%$ in Cambodia, 26.2\% in Laos, and $23.7 \%$ in Thailand [19].

The seroprevalence of Gnathostoma spp. (mostly presumed to be G. spinigerum) infection in our study was $25.5 \%$. In the Ho Chi Minh Hospital, Gnathostoma infection was 15.6\% [13], but in the community, the prevalence was $6.8 \%$ in the middle of the country [20] and $17.3 \%$ in the south of the country [14]. The prevalence of cysticercosis in this study was $12.8 \%$. In Ho Chi Minh Hospital, the prevalence was 9.8\% [13] and $4.9 \%$ [12]. In the laboratory of Hanoi Hospital, the prevalence was $15.8 \%$ [9], and in the community, the infection rate in the north was $7.2 \%$, and that in the south was $4.3 \%$ [9] and 5.1\% [14].

Fasciola spp. infection was positive in $11.2 \%$ among 1,120 examined patients. In the laboratory of Ho Chi Minh Hospital, its prevalence was $11.2 \%$ [13] and 5.9\% [12]. In the community, Fasciola infection rate was $11.0 \%$ [21] and 7.8\% [22] in the middle of the country, and that in the north was $19.3 \%$ [14]. A. cantonensis infection was positive in $10.5 \%$. In another study using PCR technique demonstrated that A. cantonensis was responsible for $67.3 \%$ of 55 cases of eosinophilic meningitis from a cohort of 1,690 adult patients at a tertiary hospital in southern Vietnam [23]. The prevalence of $C$. sinensis infection was $8.7 \%$. In the community, where local people used to eat raw fish, the prevalence was up to $40.0 \%$ [9]. C. sinensis infection rate was higher in males than in females.

Most of the patients in this study had multiple infections (53.0\%) and mono-infection was lower (11.1\%); most of the patients were infected with 2-3 helminth species. The highest prevalence was seen in the age group of 51-70 (76.0\%), and the lowest was in the age group of 5-10 (34.0\%). In another study in Ho Chi Minh Hospital, the proportion of multiple helminthiases was $45.7-54.3 \%$ [12]. In the community, it was shown that Toxocara infection in the age group of $>15$ years was higher than that in the age group of $\leq 15$ years $(19.9 \%$ and $12.8 \%$, respectively) [15]. The number of patients was the highest in May, June, and July, and this was similar with the results of De et al. [10] for a fascioliasis study in 2020 [10].

In conclusion, the overall seroprevalence of helminthic infections in the Parasitology Laboratory of Hanoi Medical University Hospital in 2018 was 64.0\%, which included toxocariasis $(59.0 \%)$, strongyloidiasis $(46.3 \%)$, gnathostomiasis (25.5\%), cysticercosis $(12.8 \%)$, fascioliasis $(11.2 \%)$, angiostrongyliasis (10.5\%), and clonorchiasis (8.7\%). Most of the 
patients had multiple infections with 2-3 species of helminths. Eosinophilia was observed in $80.2 \%$ of the total seropositive patients.

\section{ACKNOWLEDGMENTS}

This research was funded by the Vietnam National Foundation for Science and Technology Development (NAFOSTED) under a grant no. 106-YS.05-2014.08, and collaborated with the National Hospital of Pediatrics and Bach Mai Hospital, Hanoi, Vietnam.

\section{CONFLICT OF INTEREST}

We have no conflict of interest related to this work.

\section{REFERENCES}

1. Center for Disease Control and Prevention, USA. Fasciola [Internet]; [cited 2020 February 2]. Available from: https://www.cdc. gov/parasites/fasciola/epi.html.

2. ScienceDirect. Clonorchis sinensis [Internet]; [cited 2020 February 2]. Available from: https://www.sciencedirect.com/topics/immunology-and-microbiology/clonorchis-sinensis).

3. Smith $\mathrm{H}$, Noordin R. Diagnostic limitations and future trends in the serodiagnosis of human toxocariasis. In Holland C, Smith $\mathrm{H}$, eds, Toxocara: the Enigmatic Parasite. Wallingford, UK. CABI Publishing. 2006, pp 89-112.

4. Center for Disease Control and Prevention, USA. Parasites-Angiostrongyliasis (also known as Angiostrongylus Infection) [Internet]; [cited 2020 February 2]. Available from: https://www.cdc. gov/parasites/angiostrongylus/epi.html.

5. World Health Organization. Strongyloidiasis [Internet]; [cited 2020 February 2]. Available from: https://www.who.int/intestinal_worms/epidemiology/strongyloidiasis/en/.

6. Herman JS, Chiodini PL. Gnathostomiasis, another emerging imported disease. Clin Microbiol Rev 2009; 22: 484-492.

7. Bravo F, Gontijo B. Gnathostomiasis: an emerging infectious disease relevant to all dermatologists. An Bras Dermatol 2018; 93: 172-180.

8. Garcia HH, Gonzalez AE, Evans CAW, Gilman RH. Taenia solium cysticercosis. Lancet 2003; 362: 547-556.

9. De NV, Than PV, Minh PN, Lien PTH, Phuong TTK, Dan HT, Tue PT. Medical Parasites. Textbook. Hanoi,Vietnam. Medical Publishing House. 2016, pp 144-248.

10. De NV, Minh PN, Dung DT, Tuan BV, Dong NT, Chau NV, MasComa S. Study on fascioliasis in Vietnam from 1995 to 2019. J Malar Parasit Dis Cont 2020: No. 1: 10-17.
11. De NV, Khue PV. Parasitic Zoonoses. Education Publishing House. Hanoi, Vietnam. Education Publishing House. 2009, pp 21-147.

12. Nguyen T, Cheong FW, Liew JWK, Lau YL. Seroprevalence of fascioliasis, toxocariasis, strongyloidiasis and cysticercosis in blood samples diagnosed in Medic Medical Center Laboratory, Ho Chi Minh City, Vietnam in 2012. Parasit Vectors 2016; 9: 486.

13. Phuc LDV, Toan NB, Quang HH. Seropositive prevalence of helminthic infection in Medical Medic Center, Ho Chi Minh, 2018. J Viet Trop Dis 2020; 3: 55-61.

14. Dong LT, Minh DB, Hoàng NT, Hoai VT, Anh H, Nhu NHT, Thang ND, Thuy PTT. Situation of some helminthic infections in the southern part of Vietnam. Proc Nat Conf Parasitol 2019: 111-118.

15. Tuan BV, Chuong NV, Ty LC, Duyen TP, Nam VS. Seropositive prevalence of Toxocara in human and risk factors in Quang Ngai province. J Med Intervent 2017; 27: 572-578.

16. Gyang PV, Akinwale OP, Lee YL, Chuang TW, Orok AB, Ajibaye O, Liao CW, Chen PC, Chou CM, Huang YC, Barghouth U, Fan CK. Seroprevalence, disease awareness, and risk factors for Toxocara canis infection among primary schoolchildren in Makoko, an urban slum community in Nigeria. Acta Trop 2015; 146: 135-140.

17. De NV, Minh PN, Duyet LV, Mas-Coma S. Strongyloidiasis in northern Vietnam: epidemiology, clinical characteristics and molecular diagnosis of the causal agent. Parasit Vectors 2019; 12: 515.

18. Binh VL, Dung DT, Thanh DT, Truong TX. Situation of Strongyloides stercoralis infection in Phu Binh district, Thai Nguyen province and Ha Hoa district, Phu Tho province. J Malar Parasit Cont 2014; 3: $10-14$.

19. Schär F, Trostdorf U, Giardina F, Khieu V, Muth S, Marti H, Vounatsou P, Odermatt P. Strongyloides stercoralis: global distribution and risk factors. PLoS Negl Trop Dis 2013; 7: e2288.

20. Chuong NV, Tuan BV, Vy LTT, Quang HH, Khanh DD, Ngọc HM. Seropositive prevalence of Gnathostoma and risk factors in Mo Duc district, Quang Ngai province. J Malar Parasit Dis Cont 2020; 5: 18-23.

21. De NV, Murrell KD, Cong le D, Cam PD, Chau le V, Toan ND, Dalsgaard A. The food-borne trematode zoonoses of Vietnam. Southeast Asian J Trop Med Public Health 2003; 34 (suppl): 12-34.

22. Quy TM, Yeatman H, Flood VM, Chuong NC, Tuan BV. Prevalence and risks of fascioliasis among adult cohorts in Binh Dinh and Quang Ngai provinces-Central Viet Nam. Vietnam J Public Health 2015; 3: 46-61.

23. McBride A, Chau TTH, Hong NTTH, Mai NTH, Anh NT, Thanh TT, Van TTH, Xuan LT, Sieu TPM, Thai LH, Chuong LV, Sinh DX, Phong ND, Phu NH, Day J, Nghia HDT, Hien TT, Chau NVV, Thwaites G, Tan LV. Angiostrongylus cantonensis is an important cause of eosinophilic meningitis in Southern Vietnam. Clin Infect Dis 2017; 64: 1784-1787. 